\title{
Papel do Estado quanto à vulnerabilidade e proteção de adultos com deficiência intelectual
}

Role of the State in vulnerability and protection of adults with intellectual disabilities

Papel del Estado en cuanto a la vulnerabilidad y protección de adultos con discapacidad intelectual

Isis Laynne de Oliveira Machado ${ }^{1}$

Aline Albuquerque ${ }^{2}$

\section{Resumo}

Objetivo: analisar o papel do Estado na proteção de vulneráveis, especialmente de adultos com deficiência intelectual. Metodologia: estudo teórico alicerçado nos referenciais de vulnerabilidade desenvolvidos por Fineman, Pelluchon e Herring, contrastada com a concepção de bioética normativa. Resultados: constata-se que adultos com deficiência intelectual se encontram em situação de vulnerabilidade acrescida, o que, por si só, não justifica a intervenção impositiva em sua manifestação de vontade, sob o argumento de proteção. Conclusão: a atuação do Estado deve ser cautelosa quanto às aplicações práticas das concepções de vulnerabilidade e proteção, na medida em que esta última pode limitar o exercício da autonomia de pessoas com deficiência intelectual, ensejando dano travestido de proteção.

Palavras chave: Vulnerabilidade social. Proteção. Deficiência intelectual. Adulto.

\begin{abstract}
Objective: to analyze the role of the State in protecting the vulnerable, especially adults with intellectual disabilities. Methodology: a theoretical study based on the vulnerability references developed by Fineman, Pelluchon and Herring, contrasted with the conception of normative bioethics. Results: we find that adults with intellectual disabilities are in a situation of increased vulnerability, which, in itself, does not justify tax intervention in their manifestation of will, under the protection argument. Conclusion: the State must be cautious about the practical applications of conceptions of vulnerability and protection, insofar as the latter can limit the exercise of the autonomy of people with intellectual disabilities, thus providing protection transvestite damage.
\end{abstract}

Keywords: Social vulnerability. Protection. Intellectual disability. Adult.

\section{Resumen}

Objetivo: analizar el papel del Estado en la protección de vulnerables, especialmente de adultos con discapacidad intelectual. Metodología: estudio teórico basado en los referentes de vulnerabilidad desarrollados por Fineman, Pelluchon y Herring, contrastada con la concepción de bioética normativa. Resultados: se constata que los adultos con

\footnotetext{
${ }^{1}$ Doutoranda em Bioética pela Universidade de Brasília/Cátedra Unesco. Mestra em Bioética pela Universidade de Brasília/Cátedra Unesco. Especialista em Direito Público pelo Centro Universitário Projeção. Graduada em Direito pelo Centro Universitário IESB. Advogada. E-mail: isis_laynne@hotmail.com

2 Professora de Bioética e Direitos Humanos do Programa de Pós-Graduação em Bioética da UnB. E-mail: alineaoliveira@hotmail.com
} 
discapacidad intelectual se encuentran en una situación de vulnerabilidad creciente, lo que, por sí solo, no justifica la intervención impositiva en su manifestación de voluntad, bajo el argumento de protección. Conclusión: la actuación del Estado debe ser cautelosa en cuanto a las aplicaciones prácticas de las concepciones de vulnerabilidad y protección, en la medida en que esta última puede limitar el ejercicio de la autonomía de personas con discapacidad intelectual, dando daño fértil de protección.

Palabras clave: Vulnerabilidad social. Protección. Deficiencia intelectual. Adulto.

\section{Introdução}

A condição de pessoa com deficiência intelectual, ainda que em pessoas adultas, por vezes pode se constituir como um dos fatores que limitam a expressão de vontade ou a tomada de decisão do indivíduo. Tais pessoas estão mais suscetíveis (1) a sofrerem intervenções por parte de seus cuidadores, da equipe médica ou do Estado, limitando o exercício de sua autonomia (2).

Nesse sentido, a Convenção sobre os Direitos das Pessoas com Deficiência (CDPD) dispõe que a determinação de uma deficiência deve levar em conta não apenas uma catalogação biomédica, caracterizada por sintomas e formas de expressão física de determinada doença, mas deve considerar também os aspectos sociais a que o sujeito está envolto (3), a fim de identificar situações de vulnerabilidade, exclusão e limitação de manifestação de vontade sofridas por pessoas com alguma deficiência.

O conceito de vulnerabilidade tem sido perquirido mundialmente, sendo constatada a dificuldade de sua aplicação teórico-normativa na solução de casos concretos, inclusive quando se trata de grupos comumente considerados com vulnerabilidade acrescida. Esse entendimento tem sido pautado, na maior parte dos casos, por características biológicas de determinados grupos ou pessoas, como é o caso de crianças, pessoas idosas e adultos com deficiência, sendo observados também, mas com menor regularidade, aspectos socioeconômicos e culturais. Assim, a vulnerabilidade é um conceito passível de diversas interpretações, sendo necessário o aprofundamento dos estudos especializados na temática.

A condição de vulnerabilidade acrescida constitui uma das justificativas para adoção de medidas de proteção, na tentativa de minimizar os riscos a que pessoas assim consideradas estão expostas. A problemática encontra-se então na determinação dos limites das medidas protetivas no contexto das mais diferentes situações que envolvem pessoas com vulnerabilidade acrescida e no seu impacto na autonomia destas, especificamente aquelas com deficiência intelectual. 
Este artigo, de cunho teórico, tem como objetivo principal analisar a condição de vulnerabilidade de adultos com deficiência intelectual e os limites da interferência estatal na vida de tais pessoas no que tange à sua autodeterminação. Dependendo da forma como se dá, a interferência pode representar uma ação protetora, mas, por outro lado, pode constituir atos de infração a direitos inerentes às pessoas, tais como à autonomia pessoal e outros direitos de liberdade.

O marco teórico adotado neste artigo abarcou os referenciais de Herring (4), Fineman (7) e Pelluchon (8), quanto aos aspectos acerca da vulnerabilidade; o referencial da bioética normativa; e documentos internacionais de direitos humanos, quanto à necessidade e de proteção de pessoas em maior grau de vulnerabilidade que outras.

Assim, para desenvolvimento da análise pretendida, o trabalho foi estruturado da seguinte forma: inicialmente, há um delineamento quanto às concepções de vulnerabilidade, de modo a justificar a concepção adotada neste estudo, particularmente considerando seu objetivo de aplica-la às pessoas com deficiência intelectual; após, discorre-se sobre a obrigação ético-jurídica estatal de proteção de adultos com vulnerabilidade acrescida; e por fim, há a exposição de um caso ilustrativo, com o escopo de tecer reflexões acerca da temática do artigo, no que tange ao papel do Estado quanto à vulnerabilidade e à proteção de pessoas com deficiência intelectual.

\section{Perspectivas acerca da vulnerabilidade}

No sentido etimológico-conceitual, o termo vulnerabilidade possui origem latina da palavra vulnus, cujo significado é ferida. Assim, o vulnerável é aquele suscetível de ser ferido (5). O conceito de vulnerabilidade perpassa pela ideia de fragilidade e de maior exposição de alguém a ser acometido por doenças ou por situações de agressões, sejam físicas ou psicológicas. Nessa perspectiva, todos os seres humanos são vulneráveis, pois estão suscetíveis a danos, doenças, abusos e até mesmo serem explorados por outros (6).

$\mathrm{Na}$ literatura mundial e em diversos campos do conhecimento, o estudo acerca da vulnerabilidade tem ocupado cada vez mais espaço, constatando-se que sua compreensão e aplicação realizam-se de diferentes formas a depender, inclusive, da região de estudo. Andorno (6) chama atenção para o fato de que a vulnerabilidade humana deve ser levada mais a sério, principalmente na preservação de direitos humanos, visto ser improvável que esta possa ser simplesmente superada através do progresso tecnológico. 
Fineman (7) desenvolve ideia complexa quanto ao tema. Segundo a autora, apesar da vulnerabilidade humana ser universal, constante e complexa é também particular, pois é percebida por cada indivíduo de forma pessoal e única, sendo fruto de teias de relações econômicas e institucionais. Em outras palavras, vulnerabilidade seria então uma experiência, que varia de acordo com a qualidade e a quantidade de recursos disponíveis ao indivíduo. Assim, para a autora, a análise de tal situação deve considerar tanto a posição individual quanto as relações institucionais, pois a depender do contexto em que a pessoa está inserida, sua vulnerabilidade será sentida de diferentes formas.

Pelluchon (8) destaca o fato de que a vulnerabilidade não pode mais ser vista simplesmente como uma fragilidade, pois, na medida em que todos nós estamos sujeitos a sermos feridos, temos também uma responsabilidade de cuidado para com o outro. Defende que a vulnerabilidade é força, pois, ao mesmo tempo em que ela faz da pessoa dependente do auxílio de outra, permite também que o outro responda ao chamado e seja responsável por auxiliar o mais vulnerável. Nesse sentido, chama atenção para uma reconfiguração quanto ao tratamento e forma de cuidado de pessoas, especialmente as idosas e com deficiência, ressaltando que a vulnerabilidade não deve ser encarada como ausência de autonomia, devendo haver uma reavaliação quanto à relação entre a vulnerabilidade e a capacidade mental da pessoa adulta.

No que tange ao tema central do presente estudo, a relação entre vulnerabilidade e proteção de adultos com deficiência intelectual, o marco conceitual trazido por Herring (4) se mostra pertinente, uma vez que seu estudo é desenvolvido apontando casos de adultos vulneráveis, especificamente os idosos, e analisando situações de abuso no cuidado desenvolvido por familiares. $O$ autor aborda o tema salientando a importância de outros elementos, que vão além dos aspectos biológicos inerentes ao indivíduo, como reciprocidade, cooperação, solidariedade e laços de confiança estabelecidos entre as pessoas. O autor apresenta também as dificuldades em balancear os direitos de proteção e direitos quanto à autonomia de adultos vulneráveis, especialmente quando estes não querem proteção, concluindo pela necessidade de se impor limite razoável às obrigações do Estado na promoção da proteção.

Herring (4) argumenta que a vulnerabilidade pode ser compreendida de duas formas: a primeira, como uma condição humana universal, ou seja, todos os seres humanos carregam em si a condição de vulnerabilidade e estão sujeitos a sofrerem danos; 
a segunda, é o reconhecimento de que existem grupos com vulnerabilidades específicas, em regra advindas de condições biológicas, mas que podem ser geradas, agravadas ou minimizadas de acordo com o suporte social, institucional e condições socioeconômicas em que estão inseridas. Assim, o aparato estatal, ou a ausência deste, possui o condão de reduzir ou agravar as situações de vulnerabilidade, especialmente em casos de doença. Observa-se que ambas vertentes são complementares.

As proposições desenvolvidas por Herring (4), quanto à interconexão social do sujeito e à relação de dependência deste para com os demais, levam a concluir que a vulnerabilidade específica pode ser agravada, quando para além das condições biológicas do indivíduo, tais como idade, sexo e situações de doença, as conexões sociais travadas por este não the sejam benéficas, principalmente quando este está inserto em um ambiente de relações abusivas. Assim, o contexto social, condições econômicas, culturais, a qualidade de cuidados e o nível de acesso a redes de proteção social também interferem em seu estado de bem-estar (9), já que a vivência humana nos torna dependentes uns dos outros.

Ao analisar o papel do Estado quanto à proteção de adultos em situação de vulnerabilidade, Herring (4) argumenta que o reconhecimento da preservação da autonomia e dos demais direitos humanos correlatos de adultos vulneráveis demanda cautela por parte do Estado, na medida em que sua obrigação protetiva deve ser exercida de modo a buscar um equilíbrio entre os direitos de proteção e os direitos de autonomia. Com efeito, cabe ao Estado fornecer estrutura legal de apoio e de políticas públicas singulares, evitando situações de abuso doméstico por parte de familiares e da equipe de apoio envolta no cuidado de tais indivíduos, de modo consentâneo com o seu dever de respeitar a autonomia das pessoas com vulnerabilidade acrescida.

Com isso, pode-se concluir que à medida que situações de vulnerabilidade específicas são constatadas, é dever do Estado garantir, por meio de aparato legislativo e de políticas públicas, que os indivíduos obtenham acesso ao maior nível de suporte institucional a fim de que a sua vulnerabilidade seja minimizada. Assim, o dever de proteção constitui-se como uma das obrigações do Estado para com seus jurisdicionados, na preservação dos direitos humanos, especialmente quanto ao respeito à sua autonomia pessoal. 


\section{A obrigação ético-jurídica estatal de proteção de adultos com vulnerabilidade acrescida}

No campo do Direito Internacional, a tipologia obrigacional dos direitos humanos (10) ensejam os deveres de respeitar, proteger e realizar ao Estado, o que significa absterse de adentrar na esfera pessoal e de interferir na vida privada; impedir que violações de direitos humanos dos seus jurisdicionados sejam perpetradas por terceiros; e a adoção de uma série de medidas administrativas, jurídicas, políticas com vistas à efetivação dos direitos humanos. Dessa forma, embora o Estado tenha obrigações para com todos os seus jurisdicionados, destaca-se que a obrigação de proteger se torna mais acentuada quando se trata de pessoas ou grupos vulneráveis (4).

Nesse mesmo viés, a Declaração Universal sobre Bioética e Direitos Humanos (DUBDH) (12), em seu artigo $8^{\circ}$, que trata do respeito pela vulnerabilidade humana e integridade individual, traz em seu escopo o entendimento de que pessoas e grupos em situação de vulnerabilidade específica devem ser protegidos, sendo que a integridade individual de cada pessoa deve ser preservada. Tal previsão induz que os Estados signatários de tal documento possuem o dever de adotar medidas para que pessoas em vulnerabilidades específicas sejam protegidas e tenham seus direitos preservados.

No caso específico de pessoas em situação acrescida de vulnerabilidade em decorrência de estarem insertas em contextos abusivos, cabe ao Estado assegurar que haja a adequada prestação jurisdicional no caso de cometimento dos atos violadores dos direitos desse grupo.

Herring aponta que as situações de abuso variam muito notadamente quando se trata de adultos vulneráveis. Sendo assim, o Estado tem um dever geral de proteção e de intervenções específicas. Quanto ao primeiro, implica a obrigação ampla do Estado de contar com meios legais e efetivos que possam responder aos abusos cometidos contra pessoas em situação de vulnerabilidade acrescida. No que tange às intervenções específicas, o Estado deve deter conhecimento sobre o contexto abusivo para que possa ser responsabilizado por eventual omissão na proteção da vítima (4).

Fora dos contextos de abuso, há diretrizes singulares endereçadas ao exame do balanceamento entre a obrigação do Estado de respeitar a autonomia pessoal e a tomada de decisão de cada um, alicerçada no direito à privacidade e no direito ao igual reconhecimento perante a lei, e a obrigação de proteger a pessoa com vulnerabilidade 
acrescida, oriunda de outros direitos humanos. Esse balanceamento há que ser enfrentado, conforme visto, a partir de algumas premissas, quais sejam: a) a presunção de respeito à autonomia pessoal; b) decisões consideradas como irracionais ou desarrozoadas não são suficientes para desrespeitar a autonomia pessoal; c) o direito à autonomia pessoal não implica apenas a intervenção, mas também a sua promoção mediante os apoios a serem ofertados pelo Estado.

Desse modo, as sociedades democráticas fundamentadas no referencial dos Direitos Humanos têm como tarefa essencial no campo da preservação da autonomia pessoal a limitação dos órgãos e Estados a fim de evitar que adotem posturas paternalistas em relação às pessoas com vulnerabilidade acrescidas. O paternalismo consiste, sob essa perspectiva, no impedimento ou mitigação do direito de se tomar decisões sobre a própria vida, substituindo-as. Conforme Kleinig (13), respeitar a autonomia não significa deixar as pessoas sós, mas sim informá-las, acolhê-las e criar uma ambiência adequada para que possam receber informação, sopesá-la e decidir sobre sua própria vida.

Em síntese, se por um lado, se identifica o peso dado na esfera do direito internacional dos direitos humanos à proteção de grupos vulneráveis, por outro, se levanta algumas questões sobre a produção de estigma por parte do etiquetamento das pessoas vulneráveis, retirando-Ihe a voz, desconsiderando sua vontade e preferências e substituindo sua decisão. Outro ponto a ser destacado é que comumente pessoas têm sua autonomia denegada simplesmente pelo fato de serem deficientes, o que as tornam, segundo visões equivocadas e estigmatizantes, como mais vulneráveis (14).

Em verdade, a vulnerabilidade acrescida decorre da ampla gama de barreiras existentes, tal como consta do preâmbulo da CDPD, promulgada no Brasil pelo Decreto $\mathrm{n}^{\circ}$ 6.949/09: "a deficiência resulta da interação entre pessoas com deficiência e as barreiras devidas às atitudes e ao ambiente que impedem a plena e efetiva participação dessas pessoas na sociedade em igualdade de oportunidades com as demais pessoas" (15).

Nesse sentido, não são ações paternalistas de proteção que vão reduzir essas barreiras de acesso à sociedade desses grupos, e sim a promoção da autonomia pessoal.

\section{Vulnerabilidade específica de adultos com deficiência intelectual}

Segundo a American Association on Intellectual and Developmental Disabilities (AAIDD), a deficiência intelectual caracteriza-se por limitações significativas, tanto no 
funcionamento intelectual quanto no comportamento adaptativo, abrangendo também habilidades sociais e práticas cotidianas (16). A AAIDD ressalta que o funcionamento intelectual - também chamado de inteligência - refere-se à capacidade mental geral, como aprendizado, raciocínio, solução de problemas etc, sendo o teste de QI uma das maneiras de medir o funcionamento intelectual.

Geralmente, uma pontuação nesse teste com valor até 75 indica uma limitação no funcionamento intelectual. Todavia a AAIDD enfatiza que o teste de QI não deve ser considerado isoladamente. Fatores adicionais devem ser levados em conta, como o ambiente comunitário típico dos pares e da cultura do indivíduo (16).

A AAID reforça que os profissionais de saúde que analisam tais quesitos devem também considerar a diversidade linguística e as diferenças culturais na maneira como as pessoas se comunicam, se movimentam e se comportam, pois, somente com base em avaliações multifacetadas, pode-se determinar se um indivíduo possui deficiência intelectual e adaptar planos de suporte individualizados.

Para a Organização Mundial da Saúde (OMS) (17), a deficiência intelectual é uma capacidade significativamente reduzida de entender informações novas ou complexas e de aprender e aplicar novas habilidades. Isso resulta em uma menor capacidade de lidar de forma independente com escolhas, o que compromete também a interação social. Inicia-se antes da idade adulta, com um efeito duradouro no desenvolvimento do indivíduo. A deficiência depende não apenas das condições de saúde ou incapacidades, mas também de fatores ambientais e meios de apoio à participação e a inclusão plena da pessoa na sociedade.

Apesar de tal deficiência ser diagnosticada na infância, a ausência de apoio específico e de meios para a integração da pessoa com deficiência intelectual à sociedade pode acarretar estigmas na vida adulta, bem como redução dos meios para a condução de sua vida privada. As pessoas com deficiência intelectual são submetidas, com maior frequência, a medidas restritivas de sua liberdade, por meio do uso excessivo da curatela e do desrespeito à autonomia (1).

Importante destacar que a CDPD (15) dispõe que pessoas com deficiência são aquelas que detêm impedimentos duradouros de natureza mental, física, intelectual ou sensorial, os quais podem criar obstáculos para uma participação social plena e efetiva em igualdade de condições com os demais indivíduos. A Convenção tem como propósito a 
promoção e proteção do exercício pleno e equitativo de todas as liberdades fundamentais, visando assegurar o exercício de todos os direitos humanos inerentes às pessoas, de modo a garantir sua dignidade inerente. Assim, é papel de todos os Estados signatários adotar meios para que as pessoas com deficiência possam integrar-se socialmente, sendoIhes garantido o exercício e gozo equânimes de seus direitos, frente às demais pessoas.

A Declaração de Montreal sobre a Deficiência Intelectual (18) prevê, em seu artigo $6^{\circ}$, que os Estados possuem a incumbência de providenciar serviços de apoio capazes de facilitar que pessoas com deficiência intelectual possam tomar decisões significativas sobre sua vida, visto que são detentoras dos mesmos direitos que outras pessoas. Há o reconhecimento de que elas são aptas a fazer escolhas, tomar decisões e comunicar suas preferências, para melhorar seu desenvolvimento pessoal, seus relacionamentos e sua forma de participação na sociedade, apesar das dificuldades que enfrentam.

Partindo da concepção de Herring (4), tem-se que a vulnerabilidade é condição inerente a todos os seres humanos, contudo, determinados grupos possuem vulnerabilidade acrescida, tal como adultos com deficiência intelectual. Ora, recorrentemente a autonomia de tais pessoas é afrontada, especialmente no campo da saúde, na medida em que as decisões sobre sua vida são realizadas mediante utilização exacerbada do recurso da tomada de decisão substituta, como a curatela, deixando de ofertar-Ihes suportes para tomada de decisão, que thes permitam compreender informações complexas e conduzir a própria vida. Com isso, tais pessoas acabam por tornarem-se socialmente invisíveis (1).

A obrigação de proteção deve contribuir para a promoção da autonomia pessoal da pessoa com deficiência intelectual (8). Assim, repisa-se que, diante da condição de vulnerabilidade acrescida de adultos com deficiência intelectual, a principal resposta ética deve ser a promoção da sua autonomia pessoal, o que pode implicar, mormente, a adoção de suportes para tomada de decisão.

A vulnerabilidade possui íntima conexão com as relações que travamos com outras pessoas e varia de acordo com o ambiente em que estamos inseridos. Assim, ao reconhecer que nossas ações e escolhas também interferem no modo de vida do outro, acarreta também responsabilidade em proteger outras pessoas, especialmente quando vulneráveis (6). 
Com base no exposto, constata-se que pessoas em situação de vulnerabilidade acrescida necessitam de medidas protetivas também específicas. Contudo, há que se ter cautela quanto às medidas de proteção adotadas, especialmente pelo Estado, notadamente quanto a intervenções diretas na vida de tais pessoas, já que o exercício da autonomia pessoal há que ser promovido e respeitado, mediante a implantação de uma rede de proteção social, constituída por serviços de diversas naturezas (19). Isso possibilita que façam escolhas sobre seu corpo, o tratamento a que desejam se submeter e a forma que pretendem viver, expressando sua vontade e preferências, para que, assim, possam ser socialmente participantes e atores da própria vida.

O caso ilustrativo exposto no próximo tópico propicia a reflexão acerca do papel do Estado, enquanto protetor de adultos com deficiência intelectual, e o dever de respeito e promoção da sua autonomia pessoal. Dessa forma, pretende-se demonstrar os modos pelos quais certas medidas interventivas, pautadas na ideia de proteção, podem violar os direitos humanos das pessoas com deficiência, especialmente, a intelectual.

\section{Caso ilustrativo}

Conforme notícia divulgada pela imprensa oficial do Tribunal de Justiça do Goiás (20), uma jovem de 23 anos foi esterilizada compulsoriamente sob o argumento de que possuía deficiência intelectual. De acordo com o processo, apesar de não haver documentação comprobatória específica acerca da deficiência intelectual e da incapacidade mental da jovem, o juiz entendeu que devido à deficiência intelectual, não comprovada, ela estaria "incapacitada para a vida civil". Conforme a decisão, a medida não afetaria sobremaneira sua vida, já que sua capacidade de demonstrar afeto, realizar seus projetos de vida, estabelecer relações amorosas e expressar suas vontades e desejos continuariam plenamente preservados. Na avaliação do juiz, a deficiência intelectual afetava apenas a capacidade da jovem em ter filhos e ser responsável por eles. Destacase a seguinte passagem:

\footnotetext{
A restrição ao direito de ter outros filhos, com a autorização da esterilização, é imposta à ré não abstratamente, mas em razão de suas condições pessoais, que a inabilitam para exercer as responsabilidades inerentes à criação de um novo ser. Note-se que os demais direitos existenciais da ré, tais como os de se relacionar sexualmente, expressar sentimentos, de conviver comunitariamente, permanecerão intactos. (20)
} 
Como se observa, constata-se a confusão entre os conceitos de pessoa com deficiência intelectual e incapacidade mental para tomar decisões sobre a própria vida, bem como a ausência de embasamento científico no que tange à assertiva de que a jovem não estaria apta a cuidar de um filho. Mesmo com a existência da CDPD (15) e da Lei 13.146/2015 - Estatuto da Pessoa com Deficiência - (21) a qual dispõe, em seu artigo $6^{\circ}$, inciso IV, que um dos direitos de pessoas com deficiência é ter seu direito à fertilidade respeitado, sendo vedada esterilização compulsória, o Poder Judiciário desprezou tais dispositivos ao argumento de que "inexistem políticas públicas apropriadas que disponibilizem às pessoas portadoras de necessidades especiais métodos anticoncepcionais adequados à sua condição" (20).

Nota-se então que o juízo considerou ser devida a intervenção por parte do Estado a fim de realizar a esterilização compulsória da jovem, a pedido de sua mãe, mesmo ciente de que ela possui autonomia pessoal para conduzir diversos atos de sua vida. Dessa forma, estigmas e preconceitos contra a pessoa com deficiência intelectual permeiam o Poder Judiciário, assim como posturas contrárias à CDPD e ao Estatuto da Pessoa com Deficiência. Nesse caso, constata-se que, além da ausência de evidência científica, a decisão alicerça-se em concepção contrária aos direitos humanos ao adotar posicionamento em que proteger a pessoa com deficiência intelectual consiste em violar sua integridade física e suprimir sua autonomia pessoal, sob o manto do discurso paternalista.

A intervenção e sua esterilização compulsória, ao argumento de inexistirem políticas públicas que acolham e estabeleçam formas de proteção especificas para pessoas com deficiência, especialmente a intelectual, demonstram a discriminação e o estigma vivenciados pelas pessoas com deficiência intelectual no Brasil bem como o desrespeito por parte do Poder Judiciário brasileiro de normativas internacionais de direitos humanos e o seu descaso para com o resguardo da autonomia pessoal e da dignidade dessas pessoas.

Igualmente, chama atenção a jovem ter seu corpo violado e sua autonomia pessoal suprimida com base na falência do Estado, ou seja, a pessoa com deficiência intelectual além de ser vítima da total desassistência do Estado é submetida ao Poder Judiciário, o qual retira sua condição de pessoa humana ao sujeitá-la a tratamento desumano e degradante. 
Nesse contexto, no que concerne à análise da vulnerabilidade, o Estado possui o dever de apoio através de políticas públicas que ofertem às pessoas com deficiência intelectual condições de aspirar e perceber significativamente suas capacidades, manifestar sua vontade e preferência e tomar decisões sobre a própria vida (7). O efetivo papel do Estado não deve ocorrer na forma de tomar decisões em lugar das pessoas (23), mas de reduzir as diferenças existentes em casos de vulnerabilidades específicas, a fim de que possam decidir por si mesmas acerca do seu corpo e da sua vida, exercendo sua autodeterminação. A necessidade de proteção não deve servir como argumento para intervir na escolha de pessoas com deficiência intelectual, ainda mais em situações que não envolvem riscos de dano à sua saúde ou de outrem. Por isso, deve haver o desenvolvimento de políticas públicas para que pessoas com vulnerabilidades específicas possam tomar decisões sozinhas ou apoiadas.

Assim, há que se ter extrema cautela quanto a medidas de intervenção por parte do Estado, visto que ao invés de proteger, estas podem acarretar dano, na medida em que limitam o direito à autodeterminação.

Nota-se que normativas internacionais, tanto no campo da bioética quanto no campo de direitos humanos, tem centrado esforços no sentido de demonstrar a necessidade do reconhecimento de vulnerabilidades específicas, bem como do desenvolvimento de mecanismos de proteção que não ofendam a autodeterminação das pessoas com deficiência intelectual, ao revés, que forneçam meios para o desenvolvimento desta.

Segundo Dunn, Clare e Holland (24), em primeiro lugar, para que seja eticamente defensável uma intervenção protetora na vida de uma pessoa com deficiência intelectual, as intervenções de proteção deveriam ter como desiderato principal a redução de risco de sofrer abusos, concedendo-lhes meios para que possa desenvolver estratégias de autoproteção. Em segundo lugar, as intervenções devem tomar em conta significativamente as experiências subjetivas da pessoa acerca da sua vulnerabilidade, de modo que a intervenção não colida negativamente com sua identidade, cultural e social, e as percepções pessoais acerca da própria vida. Saliente-se que a análise dos autores é realizada a partir de uma nova construção de 'adulto vulnerável', em que se analisa não apenas as características biológicas do sujeito, mas também aspectos sociais, culturais, religiosos e culturais, se alinhando com as ideias apresentadas no presente estudo. 


\section{Considerações finais}

O tema relativo à vulnerabilidade de pessoas com deficiência intelectual é extenso e complexo e merece ser aprofundado, principalmente no caso de adultos com deficiência intelectual. O reconhecimento de que somos todos vulneráveis e que, em determinados momentos da vida, estaremos mais vulneráveis que outras pessoas, leva à percepção de que a vulnerabilidade acrescida das pessoas com deficiência intelectual pode não diferir de forma substantiva das vulnerabilidades humanas, em geral.

A ideia de proteção implica na garantia de que adultos vulneráveis possam ser livres para estabelecer sua vontade e preferências, bem como possam decidir sobre sua própria vida, o que há de ser harmonizado com a obrigação do Estado para prevenir danos em relação a essas pessoas. Por isso, a proteção não deve ser vista como uma imposição por parte do Estado, mas uma possibilidade para aquele que se encontra em vulnerabilidade específica, seja acolhido e tenha preservada sua autodeterminação.

A proteção pode se tornar um argumento perigoso para a intervenção na vida de determinadas pessoas ou grupos, na medida em que pode consistir em um argumento legítimo que, em verdade, oculta estigmas e discriminação. Adultos com deficiência intelectual se encontram em situação de vulnerabilidade acrescida, o que, por si só, não justifica a intervenção impositiva em seu corpo e a supressão de seus direitos humanos, sob o manto da proteção. Assim, o cuidado e as ações estatais exigem extrema atenção quanto a aplicações práticas da concepção de proteção a vulneráveis, na medida em que esta pode limitar o exercício da autonomia de pessoas com deficiência intelectual, ensejando dano travestido de proteção.

\section{Referências}

1. Albuquerque A. Direitos humanos dos pacientes. Curitiba: Juruá, 2016.

2. Souza SD, Oliveira MCSL. Deficiência intelectual na perspectiva histórico-cultural: contribuições ao estudo do desenvolvimento adulto. Revista Brasileira de Educação Especial, v. 19, n. 2, p. 169-182, 2013.

3. Diniz D, Pereira LB, Santos WR. Deficiência, direitos humanos e justiça. 2009.

4. Herring, J. Vulnerable adults and the law. Oxford: Oxford University, 2016.

5. Patrão-Neves MC. Sentidos da vulnerabilidade: característica, condição, princípio. Revista Brasileira de Bioética 2007; 2(2): 157-172 
6. Andorno R. Is vulnerability the foundation of human rights?. In: Human Dignity of the Vulnerable in the Age of Rights. Springer, Cham, 2016. p. 257-272.

7. Fineman MA. The vulnerable subject and the responsive state. EmoRy IJ, v. 60, p. 251, 2010.

8. Pelluchon C. Taking Vulnerability Seriously: What Does It Change for Bioethics and Politics?. In: Human Dignity of the Vulnerable in the Age of Rights. Springer, Cham, 2016. p. 293-312.

9. Paranhos DGAM, Albuquerque A, Garrafa V. Vulnerabilidade do paciente idoso à luz do princípio do cuidado centrado no paciente. Saúde e Sociedade, v. 26, p. 932-942, 2017.

10. Albuquerque A, Barroso A. Curso de Direitos Humanos. Rio de Janeiro: Lumen Juris, 2018.

11. United Nations. Global Migration Group. Principles and Guidelines, supported by practical guidance, on the human rights protection of migrants in vulnerable situations. Disponível em: https://www.ohchr.org/Documents/Issues/Migration/PrinciplesAnd Guidelines.pdf.[Acesso em: 04 out 2018]

12. Organização das Nações Unidas para a Educação, a Ciência e a Cultura. Declaração Universal sobre Bioética e Direitos Humanos (DUBDH). Tradução Ana Tapajós e Mauro Machado de Prado. Brasília, DF: Universidade de Brasília, 2005. Disponível em: http://bvsms.saude.gov.br/bvs/publicacoes/declaracao_univ_bioetica_dir_hum.pdf. [Acesso em: 08 out. 2018]

13. Kleinig J. (ed.), Paternalism. Manchester University Press, 1983, 26. Apud Goold, I; Herring, J. Great Debates in Medical Law and Ethics. London: Palgrave, 2018.

14. Donnelly M. Healthcare decision-making and the Law: autonomy, capacity and the limits of Liberalism. Cambridge: Cambridge, 2011.

15. Brasil. Decreto $n^{\circ} 6.949$ de 25 de agosto de 2009. Promulga a Convenção Internacional sobre os Direitos das Pessoas com Deficiência e seu Protocolo Facultativo. Disponível em: http://www.planalto.gov.br/ccivil_03/_ato2007-2010/2009/decreto/d6949.htm. [Acesso em: 20 jun. 2018]

16. American Association on Intellectual and Developmental Disabilities (AAIDD). Definition of Intellectual Disability. Disponível em https://aaidd.org/intellectual-disability/definition [Acesso em: 13 set. 2018]

17. World Health Organization. Definition: intelectual disability. Disponível em: http://www.euro.who.int/en/healthtopics/noncommunicable-diseases/mentalhhealth/news/news/2010/15/childrens-right-tofamily-life/definition-intellectual-disability. [Acesso em: 06 set. 2018] 
18. Organização Mundial da Saúde. Declaração de Montreal sobre a Deficiência Intelectual. Montreal, Canadá. 2004. Tradução: Dr. Jorge Márcio Pereira de Andrade, novembro de 2004. Disponível em: http://www.portalinclusivo.ce.gov.br/phocadownload/ cartilhasdeficiente/declaracaodemontreal.pdf. [Acesso em: 10 set. 2018]

19. Keywood K. Vulnerable adults, mental capacity and social care refusal. Medical law review, v. 18, n. 1, p. 103-110, 2010.

20. Tribunal de Justiça do Estado De Goiás, Notícias do TJGO. 2017. Disponível em: http://www.tjgo.jus.br/index.php/home/imprensa/noticias/119-tribunal/14823-juiz-autorizarealizacao-de-laqueadura-em-mulher-de-23-anos-com-retardo-mental [Acesso em: 28 jun 2018]

21. Brasil. Lei 13.146 de 6 de julho de 2015. Dispõe o Estatuto da Pessoa com Deficiência. Disponível em: http://www.planalto.gov.br/ccivil_03/_ato2015-2018/2015/lei//13146.htm. [Acesso em: 25 jun. 2018]

22. Albuquerque A. Esterilização compulsória de pessoa com deficiência intelectual: análise sob a ótica do princípio da dignidade da pessoa humana e do respeito à autonomia do paciente. Bioethikos, São Paulo, v. 7, n. 1, p. 18-26, 2013.

23. Machado ILO. Princípio da dignidade humana à luz da Declaração Universal sobre Bioética e Direitos Humanos e da Constituição brasileira: estudo de caso: acesso a medicamentos não autorizados no país. 2017. 84 f. Dissertação (Mestrado em Bioética) Universidade de Brasília, Brasília, 2017.

24. Dunn MC, Clare ICH, Holland AJ. To empower or to protect? Constructing the 'vulnerable adult' in English law and public policy. Legal Studies, v. 28, n. 2, p. 234-253, 2008. 